\title{
Patients' Perspective of Cancer Treatment and Care in Vhembe District of Limpopo Province
}

\author{
Dorah Ursula Ramathuba ${ }^{1,2^{\star}}$, Ramutumbu Neo Jacqueline ${ }^{3}$ and Ndou ND ${ }^{3}$ \\ ${ }^{1}$ Department of Nursing, University of Venda, South Africa \\ ${ }^{2}$ Tshilidzini Hospital, Department of Health, South Africa \\ ${ }^{3}$ Department of Nursing, University of Venda, South Africa
}

"Corresponding author: Dorah Ursula Ramathuba, Department of Nursing, University of Venda, P/Bag X5050 Thohoyandou 0950, South Africa, Tel: +27 15 962 800 ; E-mail: dorah.ramathuba@univen.ac.za

Received date: May 23, 2014, Accepted date: July 28, 2014, Published date: July 30, 2014

Copyright: (c) 2014 Ramathuba DU, et al. This is an open-access article distributed under the terms of the Creative Commons Attribution License, which permits unrestricted use, distribution, and reproduction in any medium, provided the original author and source are credited.

\begin{abstract}
:
Objective: The study explored and described the experiences of patients diagnosed with cancer in Vhembe district, Limpopo Province. A qualitative research design which was phenomenological, exploratory, descriptive was used. The aim of the study was to add to the knowledge and understanding of the complex human phenomena.

Methods: A purposive theoretical sample of twelve patients who were diagnosed with different cancers within 2-5 years in a regional hospital in Vhembe district of Limpopo Province was obtained. Data was collected through indepth interviews with eight participants who were in remission phase or undergoing treatment. Data saturation occurred after in-depth interviews with eight participants, field notes were also used during data collection.
\end{abstract}

Results: The findings revealed that cancer patients experienced poor communication and attitudes, experienced body changes, sense of withdrawal and depression and problems with follow-up care.

Conclusions: Understanding the cultural perspective of what it is like to have cancer and filling the gaps of patient's expectations and addressing emotional and physical needs.

Keywords: Cancer diagnosis; Cancer patients; Cancer support; Perceptions; Uncertainity; Quality of life; Qualitative analysis

\section{Introduction}

Medical advances in cancer screening and treatment has resulted in patients surviving longer with cancer and treated as out-patients. The initial or acute phase encompass the time of diagnosis which lead to psychological distress with the diagnosis and treatment [1].

According to McCann L et al., having a chronic illness causes disorder to an individual's 'normal' daily routines and can cause biographical disruption affecting how patients perceive themselves and or how they believe others to perceive them [2]. Being diagnosed with cancer "immerses the patient into a complex web of interrelated experiences" This disruption can lead to the perception of social isolation and or of being different, compounding in a sense of feeling a failure to fit in [2]. This shows that viewing cancer as a long-term illness individuals affected by cancer need to feel cared for, supported and understood by those around them. A cancer diagnosis is not limited to a person's physical experiences, but also impacts a person's soul and spirit.

Many patients face emotional and spiritual distress and choose different strategies to cope with the situation. Kvale K et al. indicated that denial and cognitive avoidance are common coping strategies among cancer patients, hope and coping were found to be positively correlated, and hope was viewed as an outcome of coping [3]. Simon $\mathrm{CE}$ et al. conducted a study with 18 African American Christian women focusing on the role of spirituality throughout their breast cancer experiences [4]. The results indicated that, for most of the survivors, spirituality and faith assisted them throughout their breast cancer experience.

Nurses must be prepared to support the patient and his family throughout the cancer experience. According to Krumwiede KA et al. men diagnosed with prostate cancer spoke of feeling comfortable through the development of trusted connections and the unwavering support they received throughout their experience with prostate cancer [5]. All of the men indicated that support from their family was important and that it allowed them to deal with the difficult circumstances of prostate cancer. The support of family members, friends, and healthcare workers was identified by the participants as an important aspect of living with prostate cancer. Nurses should provide accurate, complete, and consistent information to help patients understand the full implications of the disease process and all treatment options, not just the treatment options available at the facility of care. Cancer diagnosis among African people is not generally accepted, most ethnic groups view the disease as a white man disease and seeking medical attention is a cause for concern as many delay or combine both types of medical treatment, mostly try the indigenous system before resorting to the western medical treatment. The study therefore aims at exploring and describing the patient's perspectives of cancer treatment and care. The study will contribute to the body of knowledge to nursing practice so that the multidisciplinary team should be culture sensitive in dealing with these patients as they are adjusting to the new disease and the treatment regimen that involves a 
lot of medical complexities in its management.Thus cancer treatment and care should bridge cultural gaps in caring, incorporate cultural differences to enable clients and families to achieve meaningful and supportive caring.

\section{Methodology}

Phenomenological, qualitative research approach was used in order to explore the experiences of cancer patients within the context of their daily lives. Phenomenology is considered a philosophy, approach, and research method that is both inductive and descriptive. Phenomenology allows the investigator to gain access into a person's world and understand the meaning of that person's experiences [6]. Phenomenology refers to knowledge as it appears to consciousness, the science of describing what one perceives, senses, and knows in one's immediate awareness and experience. Purposive and theoretical sampling was used to select participants, the criteria for selecting participants included: non-hospitalised patients, who are above $20 \mathrm{yrs}$ and experienced the diagnosis of cancer, and were now receiving treatment on outpatient basis and were willing to communicate their perception regarding cancer experience.

The sample size was twelve participants with seven women and five men; however due to data saturation five women and three men participated in the study, and represented various backgrounds and socio-economic standing. The participants were treated for various types of cancer, e.g. breast, cervical, skin, stomach and bladder. Two participants were in their second year and six have been dealing with cancer for more than five years. The rights of participants were safeguarded through informed consent and confidentiality.

\section{Data collection}

The participants were approached, purpose and objectives were explained to them and rapport was initiated, and were given a choice as to where the interviews would take place, namely at the clinic or at another venue. Participant felt comfortable in their own homes, thereafter appointments were made for the interviews. Data was collected through in-depth unstructured interviews; the interviews lasted for an hour to one and half hours. The interviews were unstructured to allow for an in-depth exploration of the key theme of the study, in particular the perspective of cancer treatment and care. Interviews began with a broadly open-ended question, specific to the purpose of the study: "What is your perception of cancer treatment and care"? This was followed by some more open ended probing questions such as "How has cancer treatment affected the quality of your life? Some questions were provoked by statements made by participants. The researcher maintained neutrality by not letting their personal feelings interfere with the interview process. Audio-recorder was used during the interview and field notes.

\section{Data analysis}

Data was analysed based on Creswell qualitative analysis, during the analysis, oral descriptions of the participants were transcribed verbatim and read separately in order to gain a general understanding [7]. Significant statements and phrases about the objectives of the study were identified. Meanings were formulated from this significant statements and phrases. The formulated meanings were then organised into clusters of themes. Results of data analysis were then integrated into a description of experiences. To increase validity, two participants were selected randomly and contacted again to read the descriptions and they agreed that the analyses represented their personal experiences. Common themes were created by merging similar statements for every category. The transcriptions were written in their ethnic language following the completion of the study and analysis, thereafter translated into English but retaining the original meaning.

\section{Trustworthiness}

The model of Guba and Lincoln of trustworthiness in qualitative research was used. The following criteria to ensure trustworthiness are truth-value, applicability, consistency and neutrality [8]. Applying strategies of credibility ensured truth-value. The researcher spend 1-2 hours interviewing and kept a reflective journal, and made observations during the interviews, checked the themes and categories of statements with the participants, and focused on their experiences of living with cancer. Applying strategies of transferability ensured applicability. The researcher provided a clear description of the demographics of participants, and gave dense description of the results with supporting direct quotation of the participants. Similarly applying strategies of dependability ensured consistency. A dense description was given of the research methods used in this study. Neutrality was ensured by confirmability. The process undertaken to conduct research was provided [8].

\section{Ethical Principles}

Ethical principles were applied accordingly following the guidelines of the Democratic Nursing Organisation of South Africa [9]. These ethical principles were applied as follows, participants were not identified throughout the study, and they were interview privately in their comfortable places. All participants gave a written consent after full explanation that they can withdraw anytime without penalty. The participants benefited through this research because they were enabled to express their feelings on their needs and plight of cancer patients in rural communities of Vhembe. All participants received feedback on the research results and we were able to form a cancer survivorship program which is in its infancy where the participants and their family members are sharing and supporting each other on improving their quality of life.

\section{Results}

Five themes were identified during analysis in which Creswell qualitative method of analysis was utilized [7]. The themes are: Poor communication and attitudes, experiencing body changes, Sense of withdrawal and depression and problems with follow-up care (Table 1)

\section{Lack of proper communication and attitudes}

Communication is important in cancer diagnosis; patients need concrete information about their treatments, prognosis and outcome of the disease

"When my results came back, I was just told I had cancer and was given a return date nothing much was explained, I tried to ask for full details the doctor just told me they are not certain". Sometimes failing to give proper information may be due to lack of knowledge in a particular field, such as general practitioners. This is supported by Nguyen GT et al. who indicated that participants noted that doctors said little and tended not to speak about cancer specifically, they 
Page 3 of 5

addressed only the chief complaints it might be because they do not want their patients to worry too much [10]. Another factor was that a doctor might not be an expert in the medical issue at hand, he might not be able to offer sufficient guidance. It is thus imperative that patients be referred to appropriate experts. However, language and cultural barriers can sometimes affect communication, and patients reluctant to ask and question issues pertaining to their health.

"Sometimes when I go for check-up, they do investigations and I don't know what they are or if it is the best treatments I should be getting, as long as I can be better from the disease"

Nguyen GT et al in their study among Vietnamese immigrants reported that patients expressed poor understanding of medical tests that they received, they felt that it is the responsibility of the doctor, that it was not their role to seek information on their own [10].

"After receiving my first chemotherapy, I felt sick, was vomiting and felt weak, and went to the clinic, the nurses sent me back, saying were you not told that these treatments does that to a person, its nothing to worry about, I had to go to a private doctor and was given some medication" This is an indication of bad attitudes by health professionals because nurses should be instrumental in providing health education as well as addressing their emotional needs.

Communicating your illness to your family can also be distressful as breaking the news may affect relationships in the family situation.

"I didn't want to tell my children that I had cancer, however they definitely noticed the changes in our house. I remember I had purple marks on my chest (for radiation treatments). My skin was pale; my hair was starting to fall out.'Cancer is usually not something children understand or have experienced. They get information and ideas from other children and what they see in everyday life, including what they see on TV. Without the right information, children may fill in gaps with their imaginations many times, what they imagine is far worse than reality.

Communication is an integral role for health professionals involved in cancer care, and should take into account that it should not cause harm, and distress to patients and families; it should be emotioncentered and provide a hopeful and supportive atmosphere. Patients should also be supported in the process on how to break news to their loved ones when they are ready.

\begin{tabular}{|l|l|}
\hline Themes & Subthemes \\
\hline $\begin{array}{l}\text { Lack of proper communication } \\
\text { and attitudes }\end{array}$ & $\begin{array}{l}\text { Poor communication of diagnosis } \\
\text { Negative attitudes of health professionals }\end{array}$ \\
\hline Adjusting to body changes. & $\begin{array}{l}\text { Acceptance of new self- image } \\
\text { Embarrassment of body changes }\end{array}$ \\
\hline $\begin{array}{l}\text { Symptomatic offects } \\
\text { treatments }\end{array}$ & $\begin{array}{l}\text { Experiences of activity intolerance } \\
\text { Experiencing of embarrassment of body } \\
\text { changes }\end{array}$ \\
\hline Withdrawal and depression & $\begin{array}{l}\text { Feelings of emptiness and isolation } \\
\text { Emotional and psychological pain }\end{array}$ \\
\hline Problems with follow-up care & $\begin{array}{l}\text { Interrupted services } \\
\text { Infrastructural problems }\end{array}$ \\
\hline
\end{tabular}

Table $1:$ Themes and Subthemes

\section{Adjusting to body changes}

Cancer and its treatment can cause physical changes. Some people feel insecure about how these changes affect their body and their selfimage.

"At least the nurses told me that I must buy a wig, as I will soon lose my hair as I was starting treatment"

"I had a urinary catheter on discharge; it was such an embarrassment, it made me feel belittled because I had to keep it for few weeks while strapped on my leg inside my trouser."

"Vhone, a zwongo leluwa! (hey it's not easy) condom catheter is really uncomfortable, and if you remove it then you wet the bed which is disgusting as an adult father figure.

"When I started treatment, the other patients I found there, they were all dark skined (vho swifhala, vha sa takadzi), and realised, I'm going to look like them, even now, my palm have changed colour"

Cancer can change your outlook. Other treatments can affect how you feel. Side effects from cancer treatment, such as weight loss or weight gain, hair loss, and skin changes can also change the way you look. Fatigue can make it harder for you to care for your appearance. Body changes from cancer treatment can range from hair loss to the loss of a limb. These kinds of changes can be hard to handle because others can see them. Many people who lose hair choose to wear scarves, wigs or hats.

\section{Symptomatic effects of treatments}

Cancer patients undergoing chemotherapy experience many symptoms which they can manage when given the appropriate amount of information. However, self-management may not be sufficient or plausible for everyone. Participants reported various side effects

"My whole body was a wreck, I felt weak and pains all over my bones"

"The medication is not doing me right, always after treatment I should be vomiting and it usually last for three days or so"

Cancer patient can become conditioned to being anxious when going to receive treatments. Many patients have had the experience of what psychologists call classically conditioned vomiting. That is, vomiting even before they get to the cancer center because of the anticipation that they will vomit after treatment.

"Since I don't have appetite after treatment, my bowels don't work well, they become irritable and experience some loose stool, and I can tolerate (delele li a dzula) slippery green vegetable." at least it stays in my stomach"

"I am working, but no longer productive as before and my employer is understanding, so I work at the parcel counter due to weakness and loss of memory"

Side effects such as insomnia, fatigue and difficulties with memory and concentration can also wreak havoc in the lives of patients. Cancer treatment is an ongoing challenge, after treatment, patients do not return to a pre-cancer diagnosis state. Breast cancer patients $(n=1051)$ in the study of Hoybye MT et al., suffered from cancer or cancer treatment-related late effects before they started a rehabilitation program [11]. Many of these patients suffered from fatigue (66\%), lack of concentration (46\%) and joint or muscle pains (49\%), less from digestive- (18\%) and urinary problems (11\%). Particularly endocrine 
symptoms may have a substantial impact on quality of life. Some patients experience moodiness or are confused or unclear as to where they are. This may be the result of certain medications. These effects of treatments are called "iatrogenic effects" which is a fancy way of saying treatment-related effects. Many of these effects are temporary and eventually go away. They are not life threatening and the well-being of the patient improves and anxiety is reduced if information is provided about managing the side-effects.

\section{Withdrawal and depression}

Cancer diagnosis affect the quality of life, once diagnosed a person emotional and psychological state becomes disturbed.

Having cancer or treatment can also affect your body image. When your skin color change and start wasting due to side-effects of treatment, you are said to be having AIDS. You may feel less confident or afraid of rejection.

"You may feel numb or confused, angry about the unwanted changes cancer will bring to your life, sometimes you think of taking chances by taking African treatment and mix with hospital treatment because you need to be healed"

"When the news broke about my diagnosis, I was shocked and felt afraid and empty, just saw death starring in my face"

"I started to be alone, I was reluctant to go out, there was like this thing on my throat that I felt like crying and it was as if I was losing concentration"

"I felt sorry for myself, and I could not talk about it, I was just hurting from the inside"

These narratives indicates the world view of cancer among black communities, cancer is not seen as a disease like any other chronic condition, it's like a death sentence and others delays seeking medical health and consult traditional healers first as the sometimes associate it with sorcery or witchcraft. Literature suggests that acknowledging and responding to the patients' verbal and non-verbal cues is an important focus for health professionals, as patients respond to the news in a variety of ways [12]. Some patients find receiving bad news difficult and react with disbelief, humor, denial, fear, hope (both realistic and unrealistic) guilt, anxiety and prolonged rage. Reactions to specific family members may include shielding and anticipatory grief [13].

\section{Problems with follow-up care}

The participants reported several problems with follow-up care, one participant said "It's so frustrating because sometimes you go for follow-up and you do not see the same doctor that consulted or treated you before, thinking that he may be able to understand your problems, it's like repeating your complaints time and again with no breakthrough". Another participant indicated that "sometimes your files get lost or are misplaced and they open a new file for you with some of the reports missing and the care becomes inefficient and not effective at all". Furthermore problems of resources were highlighted like "At times the machines are not working, and no test can be done to assist with further management or the very doctor or surgeon is on leave and one cannot be assisted because he is the only one and even your complaints cannot be addressed".

Follow-up treatment care causes much anxiety to patients because they need information about the progress of their conditions and be reassured that the prognosis is good, so lack of communication can create problems, issues relating to faulty equipments or those that are not working should be reported early to the referring hospital so that patients cannot travel unnecessary. Oshima $S$ et al. are of the opinion that follow-up should typically focus on detection and early disease recurrence and management of physical and psychological adverse effects. Follow-up treatment is important when done in the same hospital by the same doctors that treated the patients because they will be having an understanding on how patients experience follow-up and post treatment care.

\section{Discussions}

The findings demonstrated that a substantial number of patients still have problems with cancer diagnosis, how it has been communicated, and communication dynamics related to terminology, medical test and the side effects of treatments and adjusting to body changes, all these factors leads to high levels of anxiety, depression and high levels of distress. Some patients felt that it's easier for them to face the reality of something new or scary if they learn as much as they can about it. This is especially true when you are dealing with a complex group of diseases like cancer. There's often a great fear of the unknown and uncertainty about what's going to happen because cancer is usually associated with death and it causes emotional and psychological distress, thinking about the future and one's dependents. Knowledge can help lessen the fear of the unknown. Early and appropriate psychosocial support and physical rehabilitation could enhance the cancer patients' quality of life, facilitate their adjustment process and possibly prevent them from developing chronic psychiatric disease.

The problems associated with treatments such as side-effects of medications has a negative impact of the patient's perspective because HIV in our rural communities has a negative connotation, for women is associated with women of low morals and one is scorned, so being associated with such diseases causes emotional and psychological pain. Furthermore body changes and adjusting to new lifestyle due to cancer its very disturbing, especially for the males, sexually is a very important aspect among Africans since a man must display his manhood by having many wives and off-springs, to be seen as a respectable man in the community. Maintaining the privacy or confidentiality can also be problematic because of the polygamous situation and usually it is the elder woman who must provide the constant support during the illness and can be very burdensome as she is older than the rest of the wives and it's a cultural accepted norm. Hiccups of follow-up care stemming from chemotherapy, surgery, radiation treatment and hormone therapy rarely exist in isolation and care for these problems are fragmented, as some doctors believe certain problems can go untreated, regarding them as minor or will be better with time, such information does not provide emotional comfort for the patient instead causes more anxiety for the patient. Further, oncologists and surgeons are often poorly linked to physical therapists that may be able to help with side effects, so it is important to take care of the needs of the patient and refer for further management. Furthermore patients reported poor service delivery when going for follow-up and finding resources being inadequate or absent; this increases level of anxiety and increases the level of dissatisfaction [14].

\section{Limitations}

The study was exclusively conducted in one district of Limpopo Province. Therefore generalization of findings is not possible. 
Page 5 of 5

However, there is a possibility and need for research to be replicated in other districts among other ethnic groups. The sample of participants had limited type of cancers, it may be necessary that a wide range of cancers be included in order to get rich narrative data and participants perspectives regarding their cancers.

\section{Conclusion}

The study reveals opportunities for providing comprehensive cancer care both for cancer patients and their relatives. Patients' psychological problems, depression, burden of suffering and particularly high levels of treatment-related symptoms suggest substantial needs for ongoing supportive care and for well-directed and effective symptom management in clinical follow-up. Sexual problems should be an important issue in counselling. Doctors and nurses should be aware of relatives' high needs for information and support. Therefore, continued assessment of psychological problems of the patients' and relatives' needs and of the patients' symptoms may provide a basis for purposeful counselling and education. Rehabilitation programmes should be developed for patients and their relatives and implemented in their communities, in primary health care settings, to support them in their long-term adjustment process.

Cancer is not a common disease among black communities, even those diagnosed with cancer are reluctant to talk about it, and hence they feel isolated, lonely and secluded. The study recommends intensive educational campaigns and outreach about cancer as a diagnosis, management of different cancers and lifestyle modification, counselling and rehabilitative programmes. Interventions by oncology nurses in teaching the patient and caregivers the physical and psychological care can assist in families adapting to cancer through formation of support groups to provide supportive communication, counselling, and educational support in improving the quality of life. Future study is needed to explore how the indigenous foods and plants have a role in cancer care and easing the symptomatic effects of cancer treatment.

\section{Conflict of Interest}

The authors declare that there is no conflict of interest.

\section{Acknowledgement}

The authors thank the patients and their relatives who participated in this study for their valuable contributions.

\section{References}

1. Golant M, Haskins NV (2008) "Other cancer survivors": the impact on family and caregivers. Cancer J 14: 420-424.

2. McCann L, Illingworth N, Wengström Y, Hubbard G, Kearney N (2010) Transitional experiences of women with breast cancer within the first year following diagnosis. J Clin Nurs 19: 1969-1976.

3. Kvale K, (2007) Do cancer patients always want to talk about difficult emotions? A qualitative study of cancer inpatients communication needs. European Journal of Oncology nursing 11: 320-327.

4. Simon CE, Crowther M, Higgerson HK (2007) The stage-specific role of spirituality among African American Christian women throughout the breast cancer experience. Cultur Divers Ethnic Minor Psychol 13: 26-34.

5. Krumwiede KA, Krumwiede N (2012) The lived experience of men diagnosed with prostate cancer. Oncol Nurs Forum 39: E443-450.

6. Wilson D, Washington G (2006) Retooling phenomenology: Relevant methods for conducting research with African American women. The Journal of Theory Construction \& Testing, 11:63-66.

7. Creswell JW (2009) Research design: Qualitative and Quantitative Mixed Methods Approaches. Thousand Oaks, California: Sage.

8. Lincoln YS, Guba EG (1985) Naturalistic inquiry. London: Sage.

9. Democratic Nursing Organisation of South Africa. Ethical considerations in nursing (1998) Pretoria: DENOSA.

10. Nguyen GT, Barg FK, Armstrong K, Holmes JH, Hornik RC (2008) Cancer and communication in the health care setting: experiences of older Vietnamese immigrants, a qualitative study. J Gen Intern Med 23: 45-50.

11. Hoybye MT, Dalton SO, Christensen J, Larsen LR, Kuhn KG, Jensen JN, et al. (2008) Research in Danish cancer rehabilitation: Social characteristics and late effects of cancer among participants in the FOCARE research project. Acta Oncol, 1-9.

12. Ryan H, Schofield P, Cockburn J, Butow P, Tattersall M, et al. (2005) How to recognize and manage psychological distress in cancer patients. Eur J Cancer Care (Engl) 14: 7-15.

13. Randall TC, Wearn AM (2005) Receiving bad news: patients with haematological cancer reflect upon their experience. Palliat Med 19: 594-601.

14. Oshima S, Kisa K, Terashita T, Habara M, Kawabata H, et al. (2011) A qualitative study of Japanese patients' perspectives on post-treatment care for gynecological cancer. Asian Pac J Cancer Prev 12: 2255-2261. 